\title{
THE WISH FOR A CHILD IN COUPLES EAGER, DISINTERESTED, AND CONFLICTED ABOUT HAVING CHILDREN
}

\author{
MARY-JOAN GERSON, JO-ANNA POSNER, and ANNE M. MORRIS
}

\begin{abstract}
Three groups of young adult couples without children were studied. They were assessed to be highly motivated to have children, moderately motivated to have children, and disinterested in having children. The groups did not differ in degree of mensured feminist sympathies nor in their memories of their own parents' degree of nurturance, demandingness, or attention. An extreme group analysis of those couples particularly motivated and unmotivated revealed differences in levels of narcissism. There were no intracouple significant correlations for these variables with the exception of a significant correlation for feminism between partners in highly and moderately motivated couples. There were some intercouple significant differences in the value ascribed to having children, notably that low motivation women were concerned about their ability to parent and low motivation men were worried about their emotional immaturity.
\end{abstract}

Decision making with regard to having children has become a major and difficult task of young adulthood. Research on fertility patterns has indicated that in the past, the decision to remain childless was generally made by default; delaying became actuality (Veevers, 1973). However, changes in sex-role norms as a result of the feminist revolution have resulted in more and more couples actively struggling with the feasibility

Mary-Joan Gerson, Ph.D., is Coordinator of Family Therapy Training, New York University Ph.D. Program in Clinical Psychology, NYU Psychology Clinic, 715 Broadway, 2nd Floor, New York, NY 10003; and in private practice in New York City. Jo-Anna Posner, Ph.D., is Clinical Director, Big Apple Learning Center, Howard Beach, New York; and in private practice on Long Island. Anne M. Morris, M.A., is a candidate for a Ph.D. in Community Psychology, New York University Graduate School of Arts and Sciences.

The American Journal of Family Therapy, Vol. 19, No. 4, 1991 (c) Brunner/Mazel, Inc. 
and desirability of having children. The struggle is sometimes brought to family therapists and counselors (Potts, 1980), and it often underlies and reflects conflicts in the second stage of the family life cycle: the transition from dyadic to a triadic structure. In the family literature, the movement from a two-person to a three-person system has been empirically studied principally from two viewpoints: factors affecting ease of transition to parenthood (Harriman, 1983; Hobbs \& Cole, 1976; Rossi, 1968) and the effect of children on marital quality (Schram, 1979; Spanier \& Lewis, 1980).

However, very little is known about the core phenomenon underlying this life cycle stage-the wish for a child in young couples. Although a recent body of literature has revealed attitudes and personality traits that differentiate individuals high and low in parenthood motivation, there is practically no information available on the shared characteristics of couples eager to have children, couples not eager to have children, or couples of mixed or conflicted motivation. Similarly, though there are some data on how parents perceive the value of having children differently than do "delays" or childless individuals (Beckman, 1976; Bram, 1975), there are practically no empirical data available that compare the value of having children for childfree couples who differ in degree of motivation.

Family theorists have speculated about the transformations that occur when a child is added to a marital dyad. Bowen (1966) stresses that the family projection process is a key means of relieving anxiety due to spousal undifferentiation; typically one child is selected for projection of the parents' own infantile needs. Framo (1970) has developed a model of irrational role assignment derived from object relations family therapy. In his model children serve to enact their parents' internalized, but dissociated, unsatisfactory childhood relationships. In fact, though parentchild and particularly mother-child relationships have been studied extensively in the psychological literature, it is only the family literature that has begun to address expectations of having children, which, after all, are the foundation of the parenting experience.

It is very possible that a deeper understanding of the perceived costs and benefits of children to couples will further account for the still-illusive factors that differentiate those who experience a comfortable versus uncomfortable transition to parenthood (Hobbs \& Cole, 1976; Waldron \& Routh, 1981). Moreover, an analysis of personality characteristics in highmotivation versus low-motivation couples may further delineate the complex relationship between having children and marital quality.

In any event, it is imperative to begin to look at the wish for a child as occurring in a couple system (Belsky, 1981). What's more, from a counseling point of view, there is a clear need for reliable, psychometrically sound data on expectations of parenthood. These data can provide a baseline for evaluating the presenting conflicts of a couple wrestling with the childbearing decision.

In the present study, we chose to analyze whether couples high, low, or mixed in motivation differed in terms of the personality variables that 
have emerged as significant in studies of parenthood motivation focused on individuals. We selected for study significant variables that seemed related to systemic hypotheses about couple motivation. Feminism has been cited as a key variable negatively related to the wish for a child (Beckman, 1976; Gerson, 1980; Lott, 1973) and affecting adaptation to parenthood by couples (Cowan \& Cowan, 1981). Memories of early childhood experiences have accounted for unique variance in both female and male parenthood motivation (Gerson, 1980, 1986; Lott, 1973) and underlie the projection process cited by Bowen (1966) and Framo (1970). Narcissism, the need to extract supplies from others (American Psychiatric Association, 1987) is highly relevant to the hypothesized use of a child to stabilize the anxiety level of spouses (Bowen, 1966). In sum, we looked at whether couples at varying levels of motivation would differ in degrees of narcissism, feminism, and the quality of their early memories of being parented. Secondly, we examined whether, and how, patterns of perceived costs and benefits of having children would emerge differently for those couples highly eager to become parents from those relatively disinterested.

\section{METHOD}

\section{Subjects and Procedures}

A nonprobability, purposive sampling technique was used. Subjects were recruited through large metropolitan health centers when they arrived for a routine examination; a small number of subjects were parttime graduate students contacted at an urban university in New York City. The intent was to include in the sample individuals in varied occupations with different income and educational levels.

The 66 couples studied had a mean age of 28.8. Approximately one third of the subjects were Protestant, one third Catholic, a quarter Jewish, and one tenth had other religious identifications. One tenth of the subjects had completed high school; two fifths of the sample completed college; approximately one half were enrolled in or had completed graduate school or a professional program. One third of the subjects earned less than $\$ 20,000$ per year, and one quarter earned more than $\$ 30,000$, with the others in the middle of that range. Ten percent of the subjects were minority group members, including Black, Hispanic, and Oriental subjects.

Sixty-five percent of the couples were married for an average of four years. Thirty-five percent described themselves as involved "in a serious relationship" of an average of two and a half years duration; slightly more than half of these "serious" couples were living together for an average of one and a half years. Married and nonmarried couples were included because counseling efforts focused on the childbearing decision have included both categories of relationship, and reports have indicated that childbearing conflicts function with equal intensity for nonmarried and married couples (Potts, 1980). 
On the basis of IPM scores (described in the Instruments section), which assessed degree of motivation, couples were divided into three categories as follows. Male and female scores were ranked on the IPM separately and the median score for each sex was determined. In the 26 high-motivation couples, both partners scored above the median on the IPM; in the 24-low-motivation couples, both partners scored below the median. Of the 16 mixed-motivation couples, 6 couples contained a male partner scoring above the median with a female partner scoring below, and 10 couples were of the opposite composition. These groups were compared. Results indicated that the couples did not differ in socioeconomic status (Hollingshead, 1965). Although there was no difference in the age of the men in the three groups, the women in the low-motivation group had an average age of 30 , which differed significantly from the average female age of 28 in the high-motivation and mixed-motivation couples.

In order to determine which costs and benefits discriminated couples who wanted children very much from those not eager to have children, an analysis was performed on an extreme group basis. Couples ( $N=10$ pairs) of which both partners scored at or above the top quartile score on the IPM were compared to couples ( $\mathrm{N}=11$ pairs) scoring at or below the bottom quartile IPM score.

Questionnaire material took from 45 minutes to one hour to complete. Couples were specifically instructed not to discuss the questionnaire material until it was completed by each member of the couple.

\section{linstruments}

Memories of Parents' Behavior. Perceptions of early chidhood care were investigated with the Parent-Child Relations Questionnaire II (Siegelman \& Roe, 1979). Subjects are asked to recall parental behavior, not attitudes, "especially about the time before [they] were 12." Three stable factors have been extracted from the PCR II: Loving minus Rejecting; Casual minus Demanding; and Attention. The PCR has been used in over 30 studies including three assessing motivation for parenthood (Gerson, 1986; Rabin \& Greene, 1968).

Narcissism. Narcissism is consensually defined in the clinical literature as a personality trait involving disturbances in interpersonal relationships such as feelings of entitlement and hypersensitivity to the evaluations of others (APA, 1987; Kohut, 1971). Though narcissistic tendencies can be present in varying degrees in different personality constellations, these tendencies are most pronounced in individuals diagnosed as having a narcissistic personality disorder. Narcissism was assessed by the Narcissistic Personality Disorder MMPI scale developed by Ashby, Lee and Duke (1979). It is an empirically derived scale whose criterion for validation and cross-validation was the diagnosis of narcissistic personality disorder, judged by psychotherapists with particular training in treating this disorder. 
Feminism II. Sympathy for the principles of the women's liberation movement were measured by the Dempewolff Feminism II Scale, Form B (Dempewolff, 1972). Factor analysis indicated dominant loading on one factor "equal ability and freedom of action for women" in the "political, intellectual and economic spheres" (Dempewolff, 1972, p. 43).

Socioeconomic Status (SES). SES was measured by using the Hollingshead (1965) Two-Factor Index of Social Position. Occupation is coded and multiplied by highest educational level completed, to derive SES rating.

Degree of Parenthood Motivation. Degree of motivation for parenthood was measured with the Index of Parenthood Motivation (IPM) (Gerson, 1983); a scale that includes five categories of motivation. Internal reliability of the IPM was measured to be .89 .

The Perceived Value of Children. The perceived benefits and costs of having children was investigated with the Parenthood Motivation Questionnaire (Kirchner \& Seaver, 1977). Factor analysis yielded 12 female and 11 male positive or benefit factors, with an overlap of 7 factors; and 10 female and male negative or cost factors, with 9 in common to both sexes. Internal reliability for the female and male, positive and negative subscales were all .95 or above (Kirchner \& Seaver, 1977).

\section{RESULTS}

\section{Personality Variables and Degree of Motivation}

There was no significant difference between the couples grouped according to degree of parenthood motivation in feminism scores $(F(2,129)$ $=.02$, n.s.) or in any of the perceptions of parents' behavior in childhood. There was only a trend towards significance in levels of narcissism $(F(2,129)=2.43, p<.10)$, as noted in Table 1 .

A further analysis of males alone revealed no significant differences between men in the three groups of couples; for females, a significant difference in mother's attention emerged $(F(2,63)=3.73, p<.05)$, though Tukey's test failed to indicate a significant difference between mean attention scores. In the extreme group analysis, narcissism emerged as a more decisive discriminating variable $(t=-2.50, p<$ $.05)$, with couples in the lowest quartile receiving significantly higher narcissism scores than couples in the highest quartile. All other differences in the extreme group comparison were insignificant.

An analysis of intracouple similarity on the two principal personality variables-feminism and narcissism-was performed. An examination of differences in intracouple correlations of feminism scores indicated that there was a significant positive correlation between partners' feminist sympathies in the high $(r=.597, p<.01)$ and mixed $(r=.634, p<$ $.01)$ motivation couples and in the highest quartile couples $(r=.720, p$ $<.01$ ) as noted in Table 2 . There were no significant intra-couple correlations for narcissism scores. 
TABLE 1

Degree of Feminism and Narcissism and Perceptions of Childhood Experience for Couples with High, Low, and Mixed Parenthood Motivation

\begin{tabular}{|c|c|c|c|c|c|c|c|}
\hline \multirow[b]{2}{*}{ Independent variable } & \multicolumn{2}{|c|}{$\begin{array}{c}\text { High } \\
(n=26 \text { pairs })\end{array}$} & \multicolumn{2}{|c|}{$\begin{array}{c}\text { Low } \\
(n=24 \text { pairs })\end{array}$} & \multicolumn{2}{|c|}{$\begin{array}{c}\text { Mixed } \\
\text { ( } n=16 \text { pairs) }\end{array}$} & \multirow[b]{2}{*}{ F } \\
\hline & $\mathbf{M}$ & SD & $\mathrm{M}$ & & $\mathbf{M}$ & SD & \\
\hline Feminicm & 92.11 & 9.56 & 9247 & 8.87 & 0101 & 1106 & .02 \\
\hline & & & & & & & \\
\hline & & & & & & & \\
\hline & & & & & 50.28 & & .99 \\
\hline $\begin{array}{l}\text { other's attention } \\
\text { CR) }\end{array}$ & 23.01 & 3.25 & 22.12 & 4.40 & 23.05 & 3.39 & .90 \\
\hline ve (PCR) & & 10.97 & & 11.65 & & 10.63 & 1.76 \\
\hline ther's & & 060 & & & & 865 & \\
\hline Father's attention ( $\mathrm{PCl}$ & 21.79 & 4.72 & 20.23 & 4.28 & 21.39 & 3.27 & 1.76 \\
\hline
\end{tabular}

$\eta<.10$

Costs and Benefits of Having Children

To investigate the qualitative differences in motivation, an analysis of ratings of the perceived costs and benefits of having children, which discriminated the highest quartile from the lowest quartile couples, was performed. Since benefits and cost factors emerged differently for women and men in the development of the Parenthood Questionnaire (Kirchner \& Seaver, 1977), the comparison of factors was across groups for each sex separately. However, though the sentence stem weightings differed, almost all of the costs and the majority of the benefits are identical for women and men. In fact the seven benefits common to both

TABLE 2

Correlations of Feminism and Narcissism Scores for Partners in High, Low, and Mixed Parenthood Motivation Couples; and Highest and Lowest Quartiles of Motivation

\begin{tabular}{llcc}
\hline Couples & & Feminism & Narcissism \\
\hline High motivation & $(n=26 \text { pairs })^{\mathrm{a}}$ & $.597^{*}$ & -.082 \\
Low motivation & $(n=24 \text { pairs })^{\mathrm{a}}$ & .236 & -.10 \\
Mixed motivation & $(n=16$ pairs $)$ & $.634^{*}$ & -.126 \\
Highest quartile & $(n=10$ pairs $)$ & $.720^{*}$ & -.349 \\
Lowest quartile & $(n=11$ pairs $)$ & -.122 & -.196 \\
\hline
\end{tabular}

"A median IPM score was determined for males and females separately. Both partners scored at or above the median for "high" group; both scored below for "low" group; one scored above and one below for "mixed" hroup.

$\because 101$ 
women and men were rated significantly higher by both partners in the highest motivation groups. Similarly, female and male benefits analogous to each other were rated significantly higher by this group, including "fulfillment through nurturance" (female: $t=5.13, p<.001$ ) and "desire to be needed and loved" (male: $t=3.08, p<.01$ ); and the pair of benefits "sex-role fulfillment" (female: $t=6.08, p<.001$ ), and "pragmatism and normative behavior" (male: $t=2.19, p<.05$ ).

However, though the highest motivation women perceived children as providing "stimulation and feelings of pride" $(t=4.48, p<.01)$, men in the highest group did not see children as significantly "adding interest to family life" $(t=1.05$, n.s.) relative to the lowest motivation men. There was no significant difference for women or men with regard to children providing "old age insurance" (women: $t=.85$, n.s.; men: $t=$ .87 , n.s.).

In terms of the perceived costs of childbearing, for the most part women and men emphasized the same or similar factors in the Highest motivation and lowest motivation groups. Both men and women who are eager to have children are less concerned about "social and personal restrictions" (women: $t=-4.85, p<.001$; men: $t=-4.32, p<.001$ ) and "worries and responsibilities of rearing a child" (women: $t=-3.68$, $p<.01$; men: $t=-3.57, p<.01$ ) than couples low in motivation. However, women with the least parenthood motivation expressed "concern about the ability to parent" $(t=-2.13, p<.05)$ whereas their male partners did not $(t=-1.95$, n.s.). However, the lowest motivation men expressed significant concern about their possible "emotional immaturity" $(t=-3.34, p<.05)$, whereas their female counterparts were unconcerned about this factor.

\section{DISCUSSION}

A striking finding in this study was that perceptions of past parental nurturance, discipline, and attention were not significantly related to parenthood motivation. Though the individual literature on parenthood motivation has stressed the importance of early experience, both theoretically (Benedek, 1959; Erikson, 1959) and empirically (Gerson, 1980, 1986; Lott, 1973), couples at various levels of motivation apparently did not differ with respect to memories of parenting styles. One possible explanation is that the effect of perceptions of past experience has not appeared as strong for individuals in their middle and late 30 s as for collegeage individuals (Gerson, 1983); apparently, as individuals solidify their identity, they feel less dependent on childhood identifications in making important life choices (Erikson, 1959). This is not to say that congruence between couples on perceptions of past nurturance and socialization is unimportant; it may be a factor in partner selection, and, of course, may crucially effect actual parenting behavior. However, differences in this dimension did not account for variability in the wish for a child.

It is interesting that narcissism did not significantly discriminate couples at the three general levels of motivation, but did differentiate the 
extreme groups of highest and lowest motivation couples. Though the family theory literature has stressed the possible projection onto children of narcissistic parental needs (Bowen, 1966; Framo, 1970), in an era of lessened pressure to have children, highly narcissistic individuals may dread parenthood because it involves the transfer of attention from the self to the child. Noteworthy is the finding that the intracouple correlation of narcissism was not significant; rather, it was the overall level of narcissism across individuals in the highest versus the lowest couple groups.

Feminism was notably not significant in accounting for differences in couple level of motivation, even in the extreme group comparison. However, a significantly positive intracouple relationship between feminism scores characterized all but the low and the lowest motivation couples. Thus, feminist sympathies seemingly do not enhance or detract from the wish for a child. Perhaps, for this cohort of couples, all of whom have reached maturity in a feminist era, the prospective role of mother or father does not present a conflict to their work-oriented and professional identities. It is difficult to say whether disagreement about feminist ideals between partners in the low-motivation couples reflects general conflict levels, which in turn make these couples less eager to become parents together, or whether specific disagreement about division of family labor is a serious deterrent to the wish for a child. The answer awaits future research; however, past research on transition to parenthood indicates that shared involvement in household tasks increases role satisfaction for both partners, and positively influences self-esteem for women (Cowan \& Cowan, 1981).

In terms of cost evaluation, it is noteworthy that women with the lowest motivation are concerned about their ability to parent, whereas their male counterparts are not so concerned. It seems that performance in parenthood is more crucial to women than to men. Indeed, socialization for women has always linked self-esteem and the fulfillment of affiliative needs (Miller, 1976). However, it is the high-motivation males who are concerned about their possible "emotional immaturity," which may reflect anxiety about the major role transition involved in having children-the renouncing of child status for adult status (Carter \& McGoldrick, 1980). Perhaps the greater emotional dependency and neediness that men in their 20s and early 30s become aware of (Levinson, 1978) appears to them as an obstacle to successful role transition.

\section{CONCLUSIONS}

There are several implications for counseling efforts directed at couples struggling with decisions about childbearing. To begin with, though discussion of past parenting styles in families-of-origin may appear useful, findings here suggest that it would be less useful than discussion of present marital attitudes. What is significant is that the "relationship identity" of the couple involve a reconstructing of past identifications to 
include procreation as a shared meaning and goal (Wamboldt \& Reiss, 1989).

Certainly the preliminary research results of this study suggest that attention to feminist principles be salient in the exploration of complementarity between such couples. Feminist issues should be addressed on at least two levels: as an overarching construct representing the exchange of nurturance and power, and as an organizational principle defining tasks and responsibilities within the marriage, including, hypothetically, childrearing. Needless to say, these levels are representative of each other, and the therapist and couple should be open to a point of transformation occurring at either level.

It is equally important to note the gender differences in the costs associated with childbearing for low-motivation couples. Perhaps the anxieties about "emotional immaturity" of husbands in the low-motivation couples is related to their wives' emphasis on adequate performance in motherhood, or vice versa. It is the couples' therapist who can explore complementary anxieties, helping, for example, a wife to feel more confident about motherhood if she and her husband redefine his adult competence.

More than anything, however, is the necessity of the couples therapist to resist a prochildbearing bias. A family systems perspective should buttress the therapist's contextual perspective which focuses therapy on strengths rather than pathologies. Thus, a couple requiring intense, mutual mirroring and attunement, in a general narcissistic sense, may feel their intimacy threatened by a needy child; however, such couples often make whole-hearted, zestful commitments to people and causes outside the marital domain, expressing generativity in a wider context. The decision to have or to forego having a child is one of the most crucial and, at a certain point, uniquely irrevocably decisions that individuals face; it merits serious and unbiased attention in family research and therapy.

\section{REFERENCES}

American Psychiatric Association (1987). Dinghustic and statistical manual of menlal disurders (3rd ed, rev.). Washington, DC: APA.

Ashby, H. V., Lee, R. R., \& Duke, F. H. (1979, August). A Narcissistic Personality MMPI Scale. Paper presented at the annual meeting of the American Psychological Association, New York.

Beckman, L. ). (1976, January). Motizations, roles and family plnuning of uomen (Final report, NIH Grant HD-07323). Los Angeles: University of California.

Belsky, J. (1981). Early human experience: A family perspective. Developmentnl Psychologu. $17,3-23$.

Benedek. T. (1959). Parenthood as a developmental phase. Journal of the American Psychoanalytic Association, 7, 389-417.

Bowen, M. (1966). The use of family theory in clinical practice. Comprehensize Psychiatry, $7,345-374$.

Bram, S. (1975). To have or have not: A social-psychological study of voluntarily childless couples, parents and to-be parents (Doctoral dissertation, University of Michigan, 1974). Dissertation Absirncts International, 35, 4250B-4251 B (University Microfilms, No. $75,639)$.

Carter, F. A., \& McGoldrick, M. (1980). The family life cycle. New York: Gardner Press. 
Chodorow, N. (1978). The reproduction of mothering. Berkeley: University of California Press.

Cowan, C. \& \& Cowan, P. (1981). Conflicts for partners becoming parents: Implications for the couple relationship. Paper presented at the annual meeting of the American Psychological Association, Los Angeles.

Dempewolff, j. (1972). Feminism and its correlates (Doctoral dissertation, University of Cincinnati). Dissertation Abstracts International, 33, 39138. (University Microfilms No. $73,03829)$.

Erikson, E. H. (1959). Identity and the life cycle. Psychological Issues, 1, 1-171.

Framo, J. L. (1970). Symptoms from a family transactional viewpoint. In N. W. Ackerman (Ed.), Family therapy in transition. Boston: Little, Brown.

Gerson, M. J. (1980). The lure of motherhood. Psychology of Women Quart'rly. 5, 207-218.

Gerson, M. J. (1983). A scale of motivation for parenthood: The Index of Parenthood Motivation. loumal of Psychology, 113, 211-220.

Gerson, M. J. (1986). The prospect of parenthood for women and men. Psychology of Women Quarterly, 10, 49-62.

Harriman, L. C. (1983). Personal and marital changes accompanying parenthood. Family Rilationts, 32(3), 387-394.

Hobbs, D. F., Jr., \& Cole, S. P. (1976). Transition to parenthood: A decade replication. journal of Marriage and the Family, 38, 723-731.

Hollingshead, A. B. (1965). Two factor index of social position. Unpublished manuscript. New Haven, CT: Yale University.

Kirchner, E. P., \& Seaver, B. (1977). Developing measures of parenthood motivation (Final report, Grant No. HD-06258-03, NICHHD, NIH). University Park: Institute for Research on Human Resources, Pennsylvania State University.

Kohut, H. (1971). The analysis of the se!f. New York: International Universities Press.

Levinson, D. (1978). The seasons of a man's life. New York: Alfred A. Knopf.

Lott, B. E. (1973). Who wants the children? Some relationships among attitudes toward children, parents and the liberation of women. American Psychologist, 28, 573-582.

Miller, J. B. (1976). Toward a new psychology of women. Boston: Beacon Press.

Potts, L. (1980). Considering parenthood: Group support for a critical life decision. American lournal of Orthopsychiatry, 50(4), 629-638.

Rabln, A. 1., \& Greene, R. J. (1968). Assessing motlvation for parenthood. lournal of Psychology, 69, 39-46.

Rossi. A. S. (1968). Transition to parenthood. Journal of Marriage and the Family, 30, 26-39.

Schram, R. W. (1979). Marital satisfaction over the family life cycle: A critique and proposal. lourral of Marriage and the Family, 41(1), 7-12.

Siegelman, M., \& Roe, A. (1979). Manual: The Parent-Child Relations Questionnaire 11. Unpublished manuscript, School of Education, City College of the City University of New York.

Spanier, G. B., \& Lewis, R. A. (1980). Marital quality: A review of the seventies. Journal of Marriage and the Family. 42(4), 825-839.

Veevers, J. F. (1973). Voluntary childlessness: A neglected area of family study. Family Coordinator, 22(2), 199-205.

Waldron, H., \& Routh, D. K. (1981). The effect of the first child on the marital relationship. Journal of Marriage and the Family, 43, 785-788.

Wamboldt, F. S., \& Reiss, D. (1989). Defining a family heritage and a new relationship identity: Two central tasks in the making of a marriage. Family Proccss, 28(3), 317-336. 